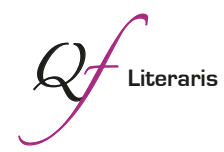

\title{
Los olores de Buchenwald. Memoria olfativa de Jorge Semprún en La escritura o la vida
}

\author{
David García Cames \\ Universidad Pontificia Bolivariana (Medellín, Colombia) \\ garciacames@gmail.com
}

\begin{abstract}
Resumen: La literatura de los supervivientes de los campos se expresa como una tensión entre la exigencia ética del testimonio y la búsqueda de la palabra precisa que sepa dar cuenta de él. Este trabajo aborda uno de los clásicos de la literatura concentracionaria, La escritura o la vida (1994) de Jorge Semprún, a partir del análisis de los mecanismos descriptivos mediante los cuales el autor se acerca a los olores que era posible percibir en Buchenwald. La memoria olfativa se constituye como una forma de construcción de la otredad cuya pregnancia queda fijada en la escritura. La persistencia de ese recuerdo sensorial simboliza para Semprún la vivencia directa de la muerte y la condición inefable de su paso por el Lager.
\end{abstract}

Palabras clave: Jorge Semprún; literatura concentracionaria; memoria olfativa; inefabilidad; otredad.

The odours in Buchenwald. Jorge Semprún's olfactory memory in Literature or Life

Abstract: The literature of the nazi camp survivors is usually expressed as a tension between the ethical requirement of testimony and the search for the right word. This paper analyses one of the classic books of Concentrationary Literature, Literature or Life (1994) by Jorge Semprún, from the study of the techniques that the author uses to describe the smells that it was possible to perceive in Buchenwald. The olfactory memory represents a form of construction of otherness whose reminiscence is fixed in writing. The persistence of the sensory memory symbolizes for Semprún the direct experience of death and the ineffable condition of his imprisonment in the Lager.

Keywords: Jorge Semprún; Concentrationary Literature; Olfactory Memory; Ineffability; Otherness. 



\section{Introducción: la búsqueda de la "verdad esencial"}

La razón última de gran parte de la obra literaria de Jorge Semprún (1923-2011) se presenta ante nosotros un día de finales de enero de 1944 a las puertas del campo de concentración de Buchenwald. Desde que el 29 de enero fuera registrado como el preso 44904 hasta el 11 de abril de 1945, día de la liberación del campo por parte de las tropas del general Patton, descubrimos en ese tiempo de supervivencia un motivo al que el escritor español afincado en Francia habría de retornar hasta el final de su vida en un incansable ejercicio de indagación ética y estética. La espiral de la memoria fijada a través de la escritura lo conducirá una y otra vez a ese lugar de partida. La necesidad de encontrar la palabra precisa para dar cuenta de aquella experiencia esencialmente "invivible", como él mismo la definió, se convertirá en la principal obsesión de un escritor cuyo nombre ha quedado ligado a los grandes autores de la llamada literatura concentracionaria. La singularidad de la Shoah en tanto forma de poder que sobrepasa "todas las formas de poder históricamente conocidas" (Mantegazza, 2006: 16) será así el objeto de su búsqueda, la clave en la que descubrir el inasible punto medio entre el relato y el testimonio, entre la memoria y la ficción.

Si bien la presencia del Lager sobrevuela toda la obra de Semprún, son cuatro las novelas centradas fundamentalmente en su paso por $\mathrm{Bu}-$ chenwald: El largo viaje (1963), Aquel domingo (1980), La escritura o la vida (1994) y Viviré con su nombre, morirá con el mío (2001). Aunque tras su muerte hayan continuado apareciendo escritos autobiográficos -como Ejercicios de supervivencia (2012), traducido este mismo año al castellano y donde detalla las torturas que sufrió antes de ser deportado-, lo cierto es que en estos cuatro libros se condensan las vivencias del autor ligadas al campo de concentración alemán y que, sin lugar a dudas, constituyen el tema recurrente de su obra. Escritos originalmente en francés, descubrimos en todos ellos esa "incesante escritura biográfica, que es al mismo tiempo la reconstrucción de sí mismo" que caracteriza el estilo de Semprún (Pla, 2004: 54). Esto

\footnotetext{
${ }^{1}$ Estos libros serían reunidos por la editorial Gallimard en el volumen Le fer rouge de la mémoire, publicado en abril de 2012 y que, además de las novelas que giran alrededor de Buchenwald, incluye una buena parte de la obra ensayística de Jorge Semprún sobre temas como el totalitarismo, el mal y los campos de concentración.
} 
permite situar la obra concentracionaria del intelectual español junto a la de otros autores como Imre Kertész o Max Aub, quienes, a pesar de notables divergencias, también recurren en sus textos a las técnicas de la ficción para acercarse a la que denominan "verdad esencial" y que, en su caso, supone ir más allá de la "verdad histórica y documental" (Sánchez Zapatero, 2010: 131). Frente a la exigencia inmediata de veracidad que caracteriza el testimonio del superviviente recién salido del campo, presente en clásicos como Primo Levi o David Rousset, la obra de Semprún recurre a la narrativa "para densificar el contenido de la realidad y para esclarecer la legibilidad de un relato" (Semprún, 2011: 411), logrando de este modo arraigarse de forma permanente en la memoria del lector y, a su vez, consiguiendo aportar una mayor verosimilitud a lo narrado.

Influido por el pensamiento de autores como Edmund Husserl, Emmanuel Lévinas o Maurice Halbwachs, la producción de Jorge Semprún sobre el exterminio nazi surge como una reflexión en torno a los mecanismos de la memoria y de su reflejo en la creación literaria. Siguiendo la premisa de Halbwachs de que un acontecimiento no "ocupa su lugar en la serie de hechos históricos hasta un tiempo después de producirse" (2004: 55), Semprún inscribe y madura su voz narrativa durante décadas en un relato que pretende erigirse en una "herramienta activa en los procesos de construcción de memoria colectiva a través de la articulación de las subjetividades" (García Díaz, 2011: 55). Los mecanismos literarios ayudan a resignificar un texto donde los elementos puramente autobiográficos conviven con otros hechos verosímiles empleados por el autor con el objetivo de reclamar del lector una mayor implicación y participación activa en el proceso de recuperación de la memoria. Tomando como punto de partida esta idea, este artículo busca analizar la descripción de los olores en el campo de concentración de Buchenwald dentro de La escritura o la vida -publicado casi cincuenta años después de la liberación y considerado por la crítica su libro más importantecomo motivo desde el que acercarse a la condición inefable de su paso por el campo. El olor se impone dentro de la narración llevada a cabo por el yo autoficcional como un leitmotiv que impregna toda la novela y que, en cierta medida, parece ofrecerse como una puerta de entrada a esa verdad que apenas resulta transmisible y comprensible mediante "la escritura literaria" (Semprún 1995: 141). 


\section{El olor y lo indecible}

La colina del Ettersberg se sitúa a pocos kilómetros de Weimar, centro canónico de la cultura alemana. Por ella pasearon Goethe y Eckermann, dando origen a una conversación que parece seguir resonando hoy en día. Sobre la colina del Ettersberg se asentaron también los barracones del campo de concentración de Buchenwald. Sobre ellos, bajo ese cielo del que un día desaparecieron los pájaros, flotaba a todas horas un extraño olor, "dulzón, insinuante, con tufos acres, propiamente nauseabundos" (Semprún, 1995: 18). Desde su primera aparición en La escritura o la vida, ese olor ejerce toda su carga emotiva dentro de la narración presentándose como un símbolo en el que la insidiosa persistencia de un recuerdo sensorial actúa como eficaz traductor del conocimiento directo de la muerte. Sobre este motivo volverá una y otra vez la prosa de Semprún, de forma obsesiva como él mismo reconoce, tratando de descifrar en cierta medida la intensidad del sufrimiento, tratando de encontrar la palabra justa que sepa nombrar, o siquiera acercarse, a la experiencia límite padecida dentro de las alambradas del Lager. En el olfato descubrimos ese sentido que Aristóteles o Hegel consideraban el más bajo, ese sentido animal, a decir de Freud, que parece exacerbarse en el proceso de deshumanización al que se ven sometidos los presos del universo concentracionario. El olor del horno crematorio se impone en la memoria sobre otras sensaciones y recuerdos, así también en el relato que le va dando forma, como testimonio de aquello que apenas puede ser expresado en palabras, tensión extrema entre la muerte y el deseo, acontecimiento originario que Semprún se siente condenado a revivir en su literatura:

Bastaría con un instante de auténtica distracción del propio ser, del prójimo, del mundo: instante de no-deseo, de quietud de más acá de la vida, en el que podría aflorar la verdad de ese acontecimiento antiguo, originario, donde flotaría el extraño olor sobre la colina del Ettersberg, patria extranjera a la que siempre acabo volviendo [...] El extraño olor surgiría en el acto en la realidad de la memoria. Renacería en él, moriría por revivir en él. Me abriría, permeable, al olor a limo de ese estuario de muerte, mareante (Semprún, 1995: 18-19).

El olor a muerte del horno crematorio irrumpe en la memoria como un lacerante "síndrome de Proust" mediante el cual el preso español se 
ve transportado a la raíz de su experiencia en el campo de Buchenwald. El olor resume y desencadena la serie de recuerdos sobre los que se construirá La escritura o la vida, es la huella que todavía se deja sentir y permanece imborrable en la memoria elaborada de Semprún. En el olor se condensa la emanación pútrida de los cuerpos en descomposición y la convivencia cotidiana de los prisioneros con el exterminio: "Me fui a acostar en la promiscuidad jadeante del dormitorio común, con el olor de la muerte que impregnaba mi alma" (Semprún, 1995: 56). La falta de palabras para definir los olores, la ausencia de un vocabulario especializado referido a este sentido y la carga moral con que se cargan los adjetivos referidos a él (Synnott, 2003: 433), nos lleva en este punto a subrayar la coincidencia entre el tono de las descripciones de los olores en el Lager y la referencia a la inefabilidad que yace en los relatos de los supervivientes de los campos. La pestilencia señala los límites del lenguaje a través de una metáfora sensorial cuya pregnancia se demuestra en la insistencia con la que se recurre a ella en los textos de la literatura concentracionaria. Sin ir más lejos, David Rousset, también deportado en Buchenwald, hablaría de "un vapor espeso, un olor infecto" en el que los hombres se confundían como bestias (2004: 18). La imagen icónica de las chimeneas de los campos nazis se combina con la potencialidad de ese recuerdo para el que apenas existen palabras, dando como resultado un símbolo cuya fuerza resulta innegable en el relato verosímil de aquellos hechos. "La inasible y viscosa presencia de la muerte", como afirma Semprún en otro de sus libros (2002: 61), encuentra en la evocación del olor de los campos una forma posible de transmitir la realidad inabarcable del exterminio. La memoria olfativa nos asalta, por lo tanto, como encarnación totalitaria del mal, metáfora originaria que no precisa de mayores explicaciones: "Los olores no son ni buscan argumentos, sino que se presentan con la evidencia de pruebas" (Diaconu, 2010: 84).

A la hora de dar forma al testimonio, el símbolo del olor de la carne quemada parece ofrecerse como una respuesta a esa necesidad de contar lo "invivible", de rememorar "algo que no atañe a la forma de un relato posible, sino a su sustancia" (Semprún, 1995: 25). Hablamos, en efecto, de la búsqueda de esa "verdad esencial" que orienta prácticamente toda la producción literaria de Jorge Semprún, de ese "núcleo fundador" de su obra y de su biografía que el escritor sometió durante décadas a un 
"complejo proceso de automitificación" (Pla, 2004: 54). El año y medio pasado en Buchenwald se acierta a expresar por momentos como una epifanía macabra que se desnuda en el olor de los cuerpos abrasados. Frente al colapso o el silencio al que se vieron sometidos muchos de los supervivientes, la vía literaria de Semprún, la combinación de autobiografía con estrategias narrativas, descubre en la rememoración desde el presente de aquellos olores de Buchenwald quizá una suerte de autoridad moral, enseñanza práctica y doliente:

Me dije que por lo menos en Buchenwald habría aprendido eso, a identificar los múltiples olores de la muerte. El olor del humo del crematorio, los olores del bloque de los inválidos y de los barracones del Revier. El olor a cuero y colonia de los Sturmführer S.S. Me dije que era un saber pertinente, ¿pero se trataría de un saber práctico? ¿Cómo estar convencido de lo contrario (Semprún, 1995: 55-56)?

Ese terrible saber del que habla el escritor le permite identificar los escenarios de Buchenwald, reconocer por ejemplo que las letrinas del Campo Pequeño podían convertirse en un "espacio de libertad" al que los S.S. no se atrevían a entrar por causa de su hediondez. Del mismo modo, la pestilencia señala la irrupción de la muerte, tal y como ocurre en la dramática escena de la agonía de Maurice Halbwachs, reconocido por Semprún como su maestro y cuyas enseñanzas sobre la memoria colectiva se pueden sentir a lo largo de toda la obra. La visita al que fuera profesor de la Sorbona dejará en el narrador ese "olor fétido de la muerte" del que no podrá desprenderse ni lavándose con agua gélida (Semprún, 1995: 56). Cuando tiempo después asista a la muerte por disentería del español Diego Morales, Semprún evocará a los dos bajo una misma imagen, metáfora de la podredumbre que consume a las mentes lúcidas en una "idéntica descomposición, idéntica pestilencia, idéntico naufragio visceral" (1995: 208). Como si se hiciera eco de los tópicos del barroco, el autor los reúne a ambos en una miasma donde la identidad queda disuelta y sometida por completo a la carroña: "Con el olor aparece la tragedia de la muerte en todo su realismo" (Diaconu, 2010: 83). En el universo esencial del campo, el olor resume y contiene lo más íntimo de la existencia: "Nada es verdad sino el humo del crematorio de Buchenwald, el olor a carne quemada" (Semprún, 1995: 254). 


\section{El rastro de la otredad}

El olor nos señala, el olor en Buchenwald marca la frontera que separa a los vivos de los que están condenados a morir. Como acabamos de ver, al cuero y la colonia de los carceleros se opone la pestilencia que acompaña el último estertor de los presos. A lo largo de La escritura o la vida "el olor no sólo contribuye a la construcción moral del yo, también a la construcción moral del grupo" (Synnott, 2003: 446). El olor cualifica una forma de relación con los otros en la que se produce un sentido de la diferencia, el otro se hace cercano o lejano según su aroma. Así, a través de un determinado olor, del valor positivo o negativo que le asociamos, puede quedar estigmatizada una persona, un colectivo o incluso toda una raza ${ }^{2}$. En el funcionamiento de un campo de concentración, en la radical separación que se produce entre víctimas y victimarios, la figura del otro puede llegar a organizarse a partir del sentido del olfato, capaz de dictaminar el papel de cada cual frente al exterminio. Así, cuando el narrador del libro se encuentre ante las tropas aliadas lo primero que hará será hablarles del humo del crematorio, del "olor a carne quemada sobre el Ettersberg” (Semprún, 1995: 25). El olor, por lo tanto, señala a los culpables como antes señalaba a los vencidos.

La construcción de la otredad convierte el olor en un rasgo que de inmediato nos repele o nos conmueve, percepción que se arraiga en nuestra intimidad reavivando y convocando algunos de nuestros recuerdos más recónditos. El olor es un sentido que tradicionalmente se asocia a la memoria, a lo que hay que sumar la capacidad que tiene de mostrarnos, en toda su desnudez, ese rostro del otro del que hablaba Lévinas y que nos interpela desde su más profunda esencia, tomándonos como rehenes. De esta forma, en la recurrencia con la que Semprún se refiere a los olores del campo de concentración de Buchenwald descubrimos esa exhortación al otro, representado en esa comunidad de víctimas que se opone a los verdugos y que, sin ir más lejos, se revela en la "fetidez

\footnotetext{
${ }^{2}$ El propio Synnott (2003: 449) recoge una cita de Hitler, tomada de Mein Kampf, donde identifica a los judíos por un supuesto olor nauseabundo que delata su "moho moral": "La pulcritud, sea moral o de cualquier otro tipo, tenía un sentido particular para esa gente. Que rehuían el agua era obvio con solo verlos y, desafortunadamente, con frecuencia también sin estarlos viendo. El olor de esa gente en caftanes me hacía sentirme mal... pero lo más repugnante era que debajo de su exterior desaseado, uno de pronto se percataba del moho moral del pueblo escogido".
} 
fraternal de las letrinas" (Semprún, 1995: 254). En el tufo al que han quedado reducidos esos hombres agolpados en los barracones se descubre su alteridad extrema, la deshumanización a la que se han visto sometidos y que apenas acierta a conceptualizarse a través de esa mención al insoportable hedor en el que se reconocen. El olor nos atrapa en la ausencia absoluta de libertad, en la negación del yo, pero al mismo tiempo nos impulsa a reconstruir en la palabra los vestigios de esa identidad devastada. Semprún rememora los horrores del campo a la par que nos indica a través de su memoria olfativa quiénes eran aquellos hombres que merecían salvarse, quienes a pesar de todo mantenían una cierta forma de dignidad en la corrupción material que los envolvía. Así sucede por ejemplo con la muerte de Maurice Halbwachs, consumido en el olor "fétido, fecal, de la muerte que crecía dentro de él como una planta carnívora, flor venenosa, deslumbrante podredumbre" (Semprún, 1995: 55). En ese relato acertamos a sentir la idea de Lévinas, quien también fuera profesor de Semprún, de que en la muerte del otro hay una apelación "que me señala, que me llama, que me reclama" y por la cual el otro se torna mi prójimo (1993: 175). La exigencia del testimonio se convierte entonces en la exigencia que formula el rostro del otro de no querer morir completamente, de mantener con vida, a pesar de todo, su memoria en el relato ejemplar de su muerte miserable.

La identidad de los presos de Buchenwald se nos muestra entonces en un rostro desnudo, cadavérico, esencial, en una "transparencia absoluta de la vida privada" (Semprún, 2002: 163). Los presos apestan pero es precisamente ese "vaho mefítico" el que los diferencia de los burócratas que programan su exterminio. El hombre aparece en una hora tragicómica donde "ha perdido su piel" (Rousset, 2004: 13), deambulando en un entorno donde la muerte se manifiesta como una descomposición irrefrenable. El olor, en efecto, nos toma como rehenes y nos hace partícipes de la experiencia concentracionaria. Nos abocamos al vértigo de sentir un cuerpo pudriéndose a nuestro lado, experimentamos la asfixia de poblar esos antros donde los que fueran hombres se amontonan como animales, vemos a lo lejos la columna de humo que sale de la chimenea del crematorio y sentimos en la evocación de ese olor la persistencia de la Shoah como hora límite del ser humano. El olor, precisamente allí, se formula entonces como "un signo natural del yo como un ser físico y moral; el olor es un símbolo del yo" (Synnott, 2003: 441). En este sentido, el olor del campo de concentración de Buchenwald construye las identidades tanto del yo como del grupo dentro de la novela de Sem- 
prún. Es un olor que nos interpela, que sale a nuestro encuentro como forma de salvar esa indecibilidad que afecta a aquellos que pasaron por los campos, una metáfora en la que se manifiesta la "concreción del no que emerge como mal" (Lévinas, 1993: 116). Es ineludible, asegura el narrador, rescatar ese olor de las llamas:

Ya no habría una memoria inmediata de Buchenwald: ya nadie sería capaz de decir, con palabras surgidas de la memoria carnal y no de una reconstrucción teórica, lo que habrán sido el hambre, el sueño, la angustia, la presencia cegadora del Mal absoluto -en la justa medida en que anida dentro de cada uno de nosotros, en tanto que libertad posible-. Ya nadie tendría en su alma y en su cerebro, indeleble, el olor a carne quemada de los hornos crematorios (Semprún, 1995: 312).

Esa necesidad de poner a salvo el horror del olvido, junto a la reivindicación de la "memoria carnal" de los testigos, se concreta en $L a$ escritura o la vida en el símbolo primordial del olor de la carne quemada. En la lectura que Semprún hace de los campos se parte de "la transformación de la memoria a través del lenguaje como un proceso paralelo al de asunción de una identidad personal y colectiva" (García Díaz, 2011: 53). Más allá de la carga política que pueda suponer esta premisa, la narración se renueva con la necesidad de contar que impulsa al superviviente, a la vez que se dota de un motivo que se fija con una poderosa pregnancia en la memoria del lector. El escritor, en su condición de deportado y antiguo miembro de la resistencia francesa, siente la obligación de mantener a salvo la experiencia de todos sus compañeros, de regresar a ese lugar donde incluso los pájaros han sido expulsados "por los olores nauseabundos del horno crematorio" (Semprún, 1995: 203). La humanidad de la que han sido despojados los presos de Buchenwald en cierta medida se les ve retornada a través del relato que da cuenta de su otredad absoluta. El mal, viene a decirnos el autor, no puede ser negado, antes al contrario, es preciso profundizar en él, hurgar en las entrañas de ese "extraño olor" para alcanzar en su evocación la memoria, el relato y quizá la verdad de quienes lo habitaron.

\section{Conclusión: después de Buchenwald}

El olor persiste en la memoria dando lugar a imágenes que reviven de forma obsesiva en el recuerdo, que hacen imposible el olvido. El yo au- 
toficcional de Semprún encuentra en su memoria olfativa un motivo al que retornar una vez tras otra como elemento narrativo y como imagen indeleble de su pasado. El olor de los hornos crematorios, la pestilencia de los presos, se constituye en metáfora del imperativo del recuerdo y de la condición "invivible" del campo. El olor, de esta forma, renace en la palabra, se nos antoja más vívido, tanto más terrible, cuanto más presente lo sentimos en el texto. Si bien, como reconoce el propio narrador, corremos el riesgo de que con la muerte de los supervivientes se convierta apenas en "una frase, una referencia literaria, una idea de olor" (Semprún, 1995: 312), la escritura no hace sino preservarlo, manteniendo en su evocación la vigencia del relato de quienes pasaron por el Lager. La "verdad literaria" de Semprún se manifiesta como una combinación de elementos narrativos con la descripción de aquellos hechos que presenció y que hasta el último día habrían de retornar desde ese tiempo significativo del pasado. El símbolo, arquetípico y tenaz, busca la palabra precisa que le permita inscribirse en la memoria colectiva de las sociedades. El olor que percibimos bajo las páginas de este libro es así tanto resultado de la memoria del testigo como de la mirada del novelista.

Sobre la colina del Ettersberg, del mismo modo que parecen seguir resonando los pasos de Goethe y Eckermann, continúa perviviendo el rastro de aquel olor, en esencia indefinible, que se diría que aún impregna el espacio del campo de concentración de Buchenwald. En su evocación descubrimos ese instinto de supervivencia que también se manifiesta en la necesidad de contar, de acudir desesperadamente a la palabra. El joven republicano español que se encontró a finales de enero de 1944 frente a la inscripción de "Jedem das Seine" ("A cada cual lo suyo") que presidía la entrada principal de Buchenwald descubriría años más tarde que allí dentro fermentó su destino de escritor, culminado quizá con la redacción de La escritura o la vida. En su búsqueda de la palabra capaz de acercarse al tuétano de la experiencia concentracionaria, Semprún llegaría a referirse a esa "felicidad insensata" (1995: 330) con la que Imre Kertész culminó su novela Sin destino: "De la felicidad en los campos debería hablarles la próxima vez que me pregunten. Si me preguntan. Y si todavía me acuerdo" (2001: 263). Todo puede tener cabida en la memoria del superviviente siempre y cuando le permita escapar de la peste del olvido. El Lager, en la imaginación de aquellos escritores que fundaron su razón literaria en él, es un universo que tiene 
que ser nombrado para pervivir, que exige la reactualización constante de un relato en el que "la humanidad del hombre, la subjetividad, es una responsabilidad por los otros" (Lévinas, 1974: 130). El olor de la carne quemada puede convertirse entonces en la única verdad, expresión de lo inefable que obliga al lenguaje a conocer sus límites, palabra memorable que actúa como símbolo, origen de un "himno indestructible" en el que todavía alcanzamos a sentir la voz de los muertos:

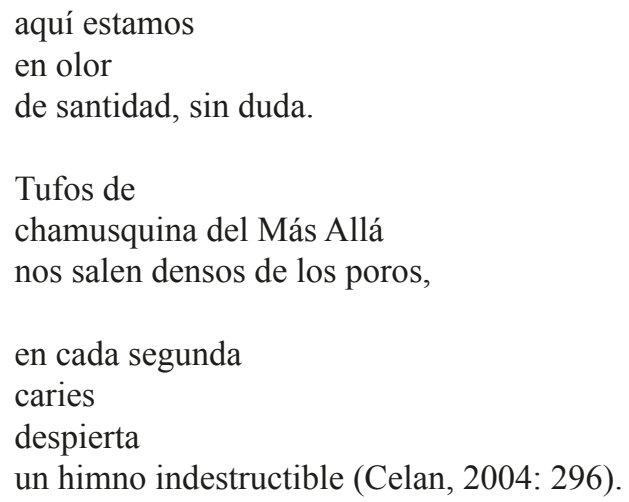

\section{Bibliografía}

Celan, Paul. 2004. Obras completas. Madrid: Trotta.

Diaconu, Mădălina. 2010. La experiencia de la alteridad olfativa. Investigaciones Fenomenológicas 2: 77-88.

García Díaz, Ana. 2011. El espíritu de la resistencia como articulador del proyecto político de la UE. Un análisis de La escritura o la vida de Jorge Semprún. $425^{\circ}$ F. Revista electrónica de teoría de la literatura y literatura comparada 5: 45-62.

Halbwachs, Maurice. 2004. La memoria colectiva. Zaragoza: Prensas Universitarias de Zaragoza.

Kertész, Imre. 2001. Sin destino. Barcelona: Acantilado.

Lévinas, Emmanuel. 1993. Entre nosotros. Ensayos para pensar en otro. Valencia: Pre-Textos.

Lévinas, Emmanuel. 1974. Humanismo del otro hombre. México: Siglo XXI.

Mantegazza, Rafaelle. 2006. El olor del humo: Auschwitz y la pedagogía del exterminio. Barcelona: Anthropos.

Pla, Xavier. 2004. Jorge Semprún, la densidad transparente y la verdad literaria. Quimera: Revista de literatura 238-239: 53-56.

Rousset, David. 2004. El universo concentracionario. Barcelona: Anthropos. 
Sánchez Zapatero, Javier. 2010. Escribir el horror: Literatura y campos de concentración. Barcelona: Montesinos.

Semprún, Jorge. 2011. Memoria del mal. Isegoría. Revista de Filosofía Moral y Política 44: 377-412.

Semprún, Jorge. 2002. Viviré con su nombre, morirá con el mío. Barcelona: Quinteto.

Semprún, Jorge. 1995. La escritura o la vida. Barcelona: Tusquets.

Synnott, Anthony. 2003. Sociología del olor. Revista Mexicana de Sociología 65(2): 431-464. 
